УДК 81'271

\title{
К ВОПРОСУ О КЛЮЧЕВЫХ ТЕНДЕНЦИЯХ В ЗАРУБЕЖНЫХ ТЕОРИЯХ ТЕРМИНОЛОГИЧЕСКОГО ПЛАНИРОВАНИЯ: СОЦИОЛИНГВИСТИЧЕСКИЙ АСПЕКТ
}

\author{
Ардашкин Игорь Борисович, \\ ibardashkin@tpu.ru \\ Национальный исследовательский Томский политехнический университет, \\ Россия, 634050, г. Томск, пр. Ленина, 30
}

\begin{abstract}
Ардашкин Игорь Борисович, доктор философских наук, профессор отделения социальногуманитарных наук Школы базовой инженерной подготовки Томского политехнического университета.
\end{abstract}

\begin{abstract}
Актуальность. Анализируются теории терминологического планирования с позиции социолингвистического подхода. Важность проводимого анализа вызвана пересмотром характера терминологической деятельности, связанного с происходящими когнитивными, лингвистическими, коммуникативными изменениями в процессе познавательной деятельности человека и социума, а также интенсивностью процессов информатизации. Целью статьи является определение основных тенденций в развитии терминологической деятельности и способах отображения обозначенных тенденций в зарубежных теориях терминологического планирования. В качестве основных методов исследования используются социолингвистический подход, главная особенность которого заключается в установлении зависимости лингвистических трансформаций от социальных процессов и наоборот. Также применяется компаративный подход в отношении сравнения основных теорий терминологического планирования на предмет отображения в них когнитивных, информационных, лингвистических и коммуникативных изменений. В качестве критерия для осуществления сопоставления указанных теорий используются онтогносеологические основания, демонстрирующие влияние онтологических структур терминологической деятельности на гносеологический аспект ее осуществления. Результаты: определены основные тенденции в терминологической деятельности, а также проанализированы одна классическая теория (общая теория терминологии Е. Вюстера) и две современные теории терминологического планирования (теория дверей М.T. Кабре и социокогнитивная теория Р. Тиммерман, К. Кереманса). Проведен компаративный анализ этих теорий, в результате которого определена трансформация понятия концепта: от ключевого параметра терминологического планирования в теории Е. Вюстера, предписывающего любому термину его семантическое наполнение прескриптивным образом, до одного из ключевых компонентов терминологического характера, посредством которого, в том числе, определяется (описывается), а не предписывается семантическое содержание термина. Выводы: пересмотр статуса понятия концепта в терминологическом планировании не приводит к тому, что тенденции носят однонаправленный характер. Эти тенденции больше свидетельствуют о том, что происходящие изменения в когнитивных, коммуникативных, лингвистических представлениях в процессе терминологического планирования носят разнонаправленный характер. В теории дверей М.Т. Кабре утверждается, что стандартизация не является теперь необходимой составляющей терминологического планирования, а социокогнитивная теория Р. Тиммерман, К. Кереманса полагает, что благодаря информационным технологиям процедуры стандартизации вполне достижимы в новых условиях реализации терминологической деятельности.
\end{abstract}

Ключевые слова: Терминологическое планирование, общая теория терминологии, терминологическая теория дверей, социокогнитивная теория терминологии, концепт. 
Терминологическое планирование, как отдельное направление научных исследований, и междисциплинарная предметная область - феномены относительно молодые. Тем не менее эта сфера в настоящее время получает свое существенное развитие в силу той огромной значимости, которую терминология играет как в науке и образовании, так и в процессе взаимодействия ученых и преподавателей с различными социальными группами [1]. Терминология фактически выступает способом трансляции научнообразовательных результатов различных предметных сфер знания для социума и на нее возлагается, с одной стороны, функция выражения специфики предметной области научных и образовательных дисциплин, с другой - функция трансляции полученных результатов потенциальным потребителям и социальным группам, которых прямо или косвенно эти результаты затрагивают. Последние аспекты предполагают, что терминология должна быть не только лингвистически корректна, но также когнитивно, коммуникативно, ценностно, социально ориентирована, без чего невозможно ее успешное функционирование в процессе развития общества.

Как данные факторы стремится учитывать терминология (терминологические теории), какие способы соблюдения и включения их использует терминологическое планирование при формировании баз и корпусов знаний, насколько их можно учесть это основные вопросы, которые будут рассмотрены и проанализированы в рамках данной статьи, которая ориентирована на социолингвистический спектр рассмотрения заявленной темы. Это обусловлено тем, что терминология, терминологическое планирование зависят не только от лингвистических факторов своего функционирования, но и от социальных, когнитивных и коммуникативных, где ключевым аспектом выступает общественный запрос на терминологические трансформации. Качество терминологии и терминологического планирования связано с социальной востребованностью последней, а ключевым критерием выступает срез социальных оценок у представителей различных социальных групп. Социолингвистический подход является наиболее подходящим способом интеграции лингвистической, когнитивной, коммуникативной, социальной составляющих терминологии и терминологического планирования [2].

Кроме того, вопросы терминологии и терминологического планирования касаются фундаментальных философских вопросов (онтологического, эпистемологического, аксиологического и т. д.), логики, специальных дисциплин, ставятся и решаются посредством междисциплинарного и трансдисциплинарного участия. Для того чтобы продемонстрировать сложный характер проблем терминологии и терминологического планирования, необходимо сделать небольшой историко-научный и философский экскурс о становлении указанных сфер научной и образовательной деятельности.

Терминология - относительно молодая наука, появившаяся примерно в 30-40-е гг. $\mathrm{XX}$ в. Становление терминологии как отдельной научной дисциплины было вызвано несколькими факторами.

Во-первых, это было связано со становлением лингвистики как самостоятельной науки в начале $\mathrm{XX}$ в., чьей отраслью являлась терминология. Становление лингвистики как науки было вызвано тем, что сегодня называют «лингвистическим поворотом» в философии и науке на рубеже XIX и XX вв., когда язык стал пристальным предметом изучения как философов (в рамках логического позитивизма, аналитической философии, феноменологии, герменевтики), так и лингвистов, математиков, социологов, психологов, биологов и других ученых.

Во-вторых, изучение языка было связано со многими логическими, онтологическими, эпистемологическими вопросами при рассмотрении последнего как индикатора проявления специфики выражения реальности, познавательных способностей человека, 
осуществления процедур формализации в логике и математике. Через указанные последние функции языка исследователи искали способы выражения ясности, однозначности, достоверности в знании. Автор не уточняет здесь подробности, связанные с проблемами реализации данных функций языка, поскольку это не является предметом настоящей статьи, но хочет отметить, что косвенно эти аспекты будут затронуты по ходу исследования.

В-третьих, активное развитие науки и научного знания (фактически начало и реализация научно-технического прогресса), активная дифференциация знания, появление новых научных дисциплин привели к необходимости решения вопроса построения соответствующего специализированного языка (языков), что и проявилось в становлении терминологии как отрасли, связанной с описанием и отображением специализированных предметных областей науки. Использование языка описания различных сфер реальности потребовало появления особого структурного элемента - термина (терминосистем), который имел отличительные характеристики по отношению к близким языковым элементам - слову, словосочетанию, понятию, дискурсу и т. д. Данные аспекты термина носили как лингвистические, так социальные, коммуникативные, когнитивные, ценностные и другие особенности.

В-четвертых, научно-технический прогресс ускорил становление техногенной цивилизации, кардинально поменяв многие сферы жизнедеятельности, внедряя научнотехнические и научно-технологические разработки во все сферы жизнедеятельности общества. В свою очередь, трансформация сфер жизнедеятельности общества привела к тому, что потребовались новые способы их описания и понимания, которые способствовали активному внедрению средств языкового описания новых техногенных разработок (терминов) в повседневный язык общества, поставив проблему адаптации специализированных языков по отношению к повседневному.

В-пятых, процессы глобализации привели, с одной стороны, к активному сближению различных стран и обществ друг по отношению другу, а с другой - к усилению неравенства между обществами и странами относительно вопросов технологического развития, что также добавило сложностей в процесс терминологического планирования и развития терминологии, связанных с вопросами заимствования современных технологий одних стран и обществ у других, но при этом без соответствующего терминологического и языкового планирования.

Это далеко не полный перечень факторов, повлиявший на становление терминологии как научной дисциплины, а также определяющий характер ее развития, но в нем представлены основные аспекты, сказавшиеся на особенностях функционирования терминологии [3]. Терминологическое планирование выступает следствием необходимости управления терминологией как наукой с позиций общества, государства, науки, культуры и других факторов. Терминология - это в первую очередь лингвистический феномен, но это не означает, что она только и ограничивается языковыми аспектами. Как в отношении самого языка существуют разные подходы, так и в отношении разделов лингвистики, изучающих различные компоненты функционирования языка (к одному из которых следует отнести терминологию), также проявляются неоднозначные позиции. Собственно, развитие терминологических теорий (теорий терминологического планирования) и обусловлено фактором пересмотра языка и его природы в лингвистике. Можно напрямую проследить эту зависимость, что отчасти будет сделано в статье.

Если изначально язык рассматривали в рамках одного из подходов как автономную лингвистическую систему (традиция Дж. Локка), где главное было выстроить язык в качестве идеальной структуры, максимально абстрагированной от общества и обще- 
ственных отношений, то после данная тенденция пересматривается. Нельзя не заметить, что был и другой подход, в котором язык максимально стремились погрузить в культуру нации (этноса), полагая, что язык - это душа нации (этноса) (И. Гердер). Сегодня приходит понимание у исследователей, что язык - сложная система, которую нельзя пытаться привести к какому-то одному знаменателю. Как пишет Е.А. Найман, «в последнее время лингвистика денатурализирует идею отдельных языков как замкнутых систем с упорядоченной грамматикой, звуками и словарем. Проблематизируя структурное понимание «языков», лингвисты пытаются перейти на новый уровень анализа, полагая, что осмысление языка не может опираться на сугубо лингвистические критерии, при которых «языки» существуют в виде абстрактных конструктов, неизменной совокупности языковых форм, изолированных от реальной социальной практики» [4, с. 53]. Эти же тенденции мы обнаруживаем в сфере терминологического планирования, особенно когда обращаемся к современным зарубежным теориям терминологии.

Тем не менее в начале XX в. при становлении терминологии как науки и первой терминологической теории господствовал позитивистский подход. В рамках данного подхода допускалось, что языковые выражения способны достаточно объективно отображать познаваемую реальность (следовательно, термин выражал онтологически ту часть предметной области, относительно которой он был создан и применялся). И именно данная установка оказалась в основе первой научной терминологической теории - общей теории терминологии Е. Вюстера (General Theory of Terminology) [5].

Небольшое уточнение, связанное с истоками формирования первой теории терминологии: до 30-х гг. XX в. терминологией занимались в основном ученые, поскольку они выступали представителями своих специальных научных областей и только они могли выразить особенность того или иного термина в своей науке. При этом ученые наблюдали рост терминов и то, что процессы их распространения осуществлялись хаотично [6]. Особенно этот процесс усилился после того, как формированием терминов занялись в первой трети XX в. инженеры и техники. Как отмечает Д. Сагедер, «в 18-19 веках ученые были лидерами в области терминологии. Однако их больше всего встревожило распространение терминов. Их беспокоило разнообразие форм и отношений между формами и концептами. Но их не интересовали ни природа концептов, ни основания для создания новых терминов.

В 20-м веке были задействованы инженеры и техники. Быстрый прогресс и развитие технологий потребовали не только обозначения новых концептов, но и согласования условий их использования. В результате практика терминологической работы стала организовываться по отдельным специальностям» [7, с. 124].

В 20-30-е гг. XX в. развитие международного сотрудничества государств, организаций, сообществ и т. д. посредством создания единого надгосударственного института в виде Лиги Наций и международных образований, функционирующих под ее крылом, с одной стороны, а также необходимости обратиться к термину, его природе и способу функционирования как лингвистическому феномену - с другой, вызвало появление общей теории терминологии (General Theory of Terminology). Интеграционные процессы коснулись и сферы науки, где требовалась стандартизация как в вопросах международного использования терминологии, так и в вопросах междисциплинарного научного взаимодействия, вызванного усиленным влиянием последнего на социальную сферу жизнедеятельности и активного применения соответствующих научных понятий в ней. Стандартизация как процесс унификации взаимодействия различных институтов требовала определенного единства в процессе взаимодействия и коммуникации, что, в свою очередь, вызывало необходимость унификации терминологической. 
Общая теория терминологии Е. Вюстера как раз и решала эту проблему. А решению этой проблемы лингвистически способствовал интерес исследователей из различных областей (логика, философия, математика, социология и др.) к языку и его способности точно отображать значения, которые понятия несли в себе относительно исследуемой реальности. Сам факт того, что стандартизация терминологии рассматривалась в качестве основной причины появления теории, был следствием установки о том, что однозначность языкового выражения являлось искомой и достижимой нормой, которая выражала особенность научного способа познания. Эта установка являлась доминирующей и активно функционировала как ключевая ценность научного сообщества того времени. И именно она самым существенным образом повлияла на становление первой теории терминологии.

Ключевым вопросом для терминологии в теории Е. Вюстера стал вопрос о природе термина. Только надо уточнить, что таким образом этот вопрос не ставился, но он проистекал из другого вопроса - вопроса об основаниях стандартизации терминологии (в варианте Е. Вюстера речь шла о создании унифицированных словарей [8]). Для того чтобы понять, как осуществлять унификацию термина, важно разобраться, как термин возникает и функционирует, каков его статус в системе знания вообще и специализированного знания в частности?

Чем термин отличается от просто слова и понятия, как формируется его значение?

Очевидно, что термин не появляется на пустом месте - он возникает в системе специализированного знания (по крайней мере, специализированное знание требует способа выражения своей семантической и синтаксической особенности). Термин в первую очередь и выполняет эту функцию.

Однако выполнение этой функции также ставит ряд вопросов, которые требуют своего решения. Если термин, например, встречается в разных научных дисциплинах, то как уточнить, о чем идет речь. Или если термин из одной дисциплины применяется вне контекста этой дисциплины (в другой дисциплине или за пределами научного сообщества). Иначе вне такого уточнения могут возникнуть расхождения в интерпретации и это приведет к многозначности, а значит, термин не выполнит свою функцию передачи специфического значения, свойственного для определенной отрасли науки. Иными словами, термин нужно обязательно использовать в связи с определенным контекстом специализированного знания. А вот данная форма отношений термина и контекста его применения оказалась никак не осмысленной учеными: либо эта связь формировалась интуитивно, неосознанно, либо решалась за счет ситуационного контекста употребления, который имплицитным образом снимал остроту вопроса о взаимодействии термина и контекста его употребления.

Контекст употребления термина (сюда важно включить аспект его формирования и функционирования) потребовал поиска соответствующего термина и получил название концепта. Сразу же оговорюсь, что в отношении концепта как понятия и термина существует целое множество подходов, которое требует отдельного рассмотрения. Но в рамках этой статьи автор ограничится данным пониманием, которое будет возможно уточняться по ходу рассмотрения темы.

Концепт в терминологии стал важнейшим понятием, поскольку именно посредством установления связи между концептом и термином и рассматривалась терминологическая деятельность [9]. Терминология как лингвистическая дисциплина рассматривалась в рамках лексикографии - науки, которая специально занималась формированием значений у слов и понятий. Но этот процесс характеризовался лингвистической автономией и реализовывался исключительно ономасиологическими и семасиологиче- 
скими стратегиями. В отношении терминологии авторы также стремились соблюдать эти способы формирования значений. Другое дело, что такого рода установка носила прескриптивный характер и больше являлась идеальной моделью, нежели практикой, учитывающей все способы установления значений у терминов.

Е. Вюстер постарался соблюсти позитивистские приоритеты при формировании своей теории терминологии. Необходимость стандартизации в области терминологии хорошо сочеталась с этими стандартами. Поэтому ключевой установкой общей теории терминологии стала норма: один концепт - один термин. Только такая установка позволяла добиться однозначности в термине, минимализации синонимии. Соответственно, стандартизация при подобной установке осуществлялась существенно легче. Кроме того, для Вюстера развитие терминологии как отдельной научной дисциплины связывалось с взаимодействием исследователей в рамках профессиональной деятельности (можно сказать, внутри профессиональной), применение терминов рассматривалось в рамках узкопрофессиональной коммуникации. Отсюда и данная установка: один концепт - один термин. Например, термин «операция» («операции») формировался через концепт какой-либо отдельной профессиональной отрасли: в рамках концепта «мышление» термин «операция» имеет одно значение, «медицина» - другое, «финансы» третье, «военное дело» - четвертое, «полиция» - пятое и т. д. Это действительно представлялось удобным в контексте специально-профессионального общения, а также позволяло проводить быструю и простую стандартизацию на международном уровне.

Важной задачей общей теории терминологии (General Theory of Terminology) Е. Вюстер считал обоснование того, почему терминология должна рассматриваться в качестве отдельной дисциплины, отличающейся в первую очередь от лингвистики. И здесь важнейшую роль играло понятие «концепт», поскольку именно использование концепта в качестве основания для обозначения термина должно было продемонстрировать разницу между терминологией и лингвистикой в вопросе его природы. Другими словами, Е. Вюстер этим хотел сказать, что в отличие от лингвистики, которая может рассматривать термин как часть своей предметной области, терминология ключевым предметом своего изучения выбирает концепт (систему концептов). И общая теория терминологии - это теория концептов, а не теория терминов, поскольку природа термина связана с областью концептов, а не областью значений.

Также Е. Вюстер конкретизировал наиболее существенные особенности в отношении отличий терминологии от лингвистики при работе с термином. Он использовал три критерия, на основании которых указанные различия можно продемонстрировать: в отношении языка, в отношении предположений об эволюции теории, в отношении методологии.

В отношении языка австрийский исследователь приводил следующие особенности терминологии: приоритет концепта; точность концепта (моносемия); однозначность термина (отсутствие синонимии); семиотическая концепция обозначений; исключительный интерес к лексике, исключая все другие уровни лингвистики; синхронная обработка терминов; приоритет письменных регистров. В отношении предположений об эволюции теории терминологии: сознательный контроль эволюции (планирование, объединение, стандартизация); приоритет международных форм обозначений; использование исключительно письменного языка. В отношении методологии: исключительное использование ономасиологического подхода (в отличие от семасиологического подхода лексикографии в лингвистике) и, следовательно, предпочтение систематического заказа [5]. 
Тем самым Е. Вюстер конкретизировал предметное поле терминологии. Кроме того, ему также удалось осуществить международную стандартизацию в области терминологии и создать целую серию унифицированных словарей в различных узкоспециальных областях.

Подобного он добился на основе следующей трактовки концепта, которая в дальнейшем подверглась пересмотру, но в период 30 -х гг. XX в. оказалась вполне приемлемой: концепт в качестве способа обозначения определенной сферы специализированных знаний (точнее, смыслового пространства, которое представлено в этом знании) понимался Е. Вюстером как универсальный феномен. Он не зависел от культурных, языковых, когнитивных и других способов получения научного специализированного знания, и поэтому не было необходимости его как-то приспосабливать и менять под данные критерии. Как пишет М.Т. Кабре, ключ к позиции, по-видимому, заключается в предположении, что концепт универсален, независим от культурных различий и что, следовательно, единственно возможная вариация - это вариация, обусловленная разнообразием языков. По мнению Вюстера, ученые и техники, владеющие определенным языком, характеризовали (или, скорее, должны характеризовать) предметную область таким же образом, чтобы единственные различия, которые могли возникнуть, были бы результатом их разных языков или их использованием альтернативных обозначений того же объекта. Оба расхождения могут нарушить профессиональное общение, и, следовательно, Е. Вюстер был стойким сторонником единого языка для научного и технического общения [10].

Однако такого рода теория терминологического планирования больше отображала не сам процесс терминологической работы, сколько то, каким образом данная деятельность должна быть организована и какие результаты должны были получаться. Во многом это задавалось теми онтологическими основаниями, которые предполагались универсальной природой концепта. Фактически получалось, что концепт мог быть выражением полярных представлений о реальности, об отображении последней в специализированном знании: любо он максимально объективно мог представлять реальность, либо максимально субъективно [11]. Однозначность концепта (моносемия) могла проистекать только из подобного рода онтологических оснований. Как полагают Б. Антиа и Й. Майкинг, эпистемологическая позиция терминологической теории объекта должна выходить за рамки наивного реализма, присущего неопозитивизму и солипсизму, воплощенному в ряде направлений конструктивизма, которые были наиболее подходящими онтологическими системами для Е. Вюрстера. Для терминологии более подходящими являются онтологические позиции, занимающие промежуточное положение между крайностями неопозитивизма и солипсизма. Подчеркнуть эти промежуточные позиции или принять широкую эпистемологическую точку зрения - значит подписаться под онтологический плюрализм, а не онтологическое единство [12, 13].

Е. Вюрстер сам понимал, что его терминологическая модель носит излишне строгий характер, который удобен при стандартизации, но не очень отражает в процессе терминологической деятельности те сложности, которые возникают при его осуществлении. Он и его последователи разработали усовершенствованную теорию терминологии, которая получила название расширенной теории терминологии (Extended Traditional Theory of Terminology). В ее рамках был пересмотрен ряд позиций общей теории терминологии. В частности, допускалась иерархия концептуальных структур, контролируемая синонимия, разговорные формы и фразеология и т. д. Но это не меняло сути проблем, которые стали появляться у терминологов. 
К 80-90-м гг. ХХ в. стали публиковаться критические статьи в отношении теории Е. Вюрстера. Не будем задаваться вопросом, почему так долго этого не происходило, а сконцентрируемся на основных критических аспектах и предложениях по развитию теорий терминологии (о причинах отсутствия критики общей теории терминологии можно почитать здесь - [10]), хотя уже основную причину автор представил выше.

Критика общей теории терминологии шла со стороны трех позиций (когнитивные науки, науки о языке, науки о коммуникации), и все эти позиции были связаны с переосмыслением концепта и его роли в формировании термина. Если лаконично выразить суть критики обшей теории терминологии и ее модернизированной версии, то можно сказать, что когнитивные исследования продемонстрировали проблематичность разделения общего и специализированного знаний (это сделать однозначно нельзя). Науки о языке продемонстрировали, что ключевыми факторами языковых изменений выступают не собственно лингвистические факторы, а социальные трансформации (появление терминологического планирования явилось потребностью социума управлять знанием и терминологией, нежели проистекало из проблем языковых). Науки о коммуникации также продемонстрировали невозможность общения исключительно в контексте узкоспециализированного формата научных дисциплин, а также актуализировали невозможность осуществления стандартизации, учитывая особенности разных национальных языков.

Более того, данная критика привела к тому, что вопрос о терминологии как науки, точнее, самостоятельной научной дисциплины, обострился. Возникли разные подходы: от признания последней в таком качестве до полного отрицания научного статуса у нее. Также возникли позиции, которые стали обходить этот вопрос стороной, полагая, что для терминологии это не важно, поскольку последняя выступает в качестве практической сферы, на основе которой осуществляется междисциплинарное взаимодействие и коммуникация. Как пишет Г. Будин, «на вопрос, является ли терминология научной (в качестве отдельной научной дисциплины), также можно ответить по-разному. В то время как Е. Вюстер, Г. Фельбер и др. десятилетиями подчеркивали, что терминология - наука (заметьте, «учение» на немецком языке в традиционном значении, как отмечалось выше, - это и практическая область знаний, и научная область исследования), другие неоднократно отрицали это (например, Х.С. Сагер, 1990) или критиковали потребность в научных дисциплинах и призвали к трансдисциплинарной интеграции без границ между дисциплинами, так что этот вопрос становится бесполезным (М.Т. Кабре, 1998)» [14, с. 14].

Однако важность терминологии и терминологического планирования в любом качестве (как науки, как социальной практики, как способа трансдисциплинарной интеграции) признают все исследователи, что заставляет искать новые способы понимания того, как лучше организовывать терминологическую деятельность и терминологическое планирование. При этом способы ее совершенствования могут осуществляться в зависимости от того, в чьих интересах это делается, поскольку для разных стейкхолдеров процесса эти улучшения могут отличаться. Одна цель может быть в случае, когда это делается в интересах ученых, другая - когда это делается в пользу государства, третья - если целевая аудитория потребители из разных социальных групп и т. д.

Ключевым фактором поиска модернизации терминологических теорий стал пересмотр понятия «концепт», характера его взаимодействия с термином. Принцип Е. Вюстера «один концепт - один термин» перестал работать, когда стало очевидно, что специализированное знание фактически невозможно отличить от общего в силу особенности протекания когнитивных, лингвистических, коммуникативных процессов. Потребовалось выявление нового характера отношений концепта с термином и знанием. 
Тут важно учитывать, что в связи с активным развитием информационных технологий способы хранения, трансляции, обработки знания изменились. Появились большие базы знаний, особые каналы потоков знаний и информации, что стало усложнять процедуру стандартизации и потребовало новых оснований для ее осуществления. Сама идея стандартизации как ключевой цели терминологии также пересматриваться.

Стало очевидно, что специализированные научные знания, представляющие собой разные предметные области, существуют совместно, а не отдельно, в общей массе знаний. Получается, что в одном измерении эти знания выражают собой разные онтологии, в другом измерении - единую онтологию, а развести эти онтологии однозначно невозможно. Поэтому концепт представляет собой такое измерение знания, мысли, восприятия, в котором возможно сочетание различных контекстов корпуса знаний, но отделение которых друг от друга невозможно. М.Т. Кабре говорит, что для решения этого вопроса необходимо найти наиболее подходящие формы совмещения такого рода контекстов знания, представляющих концепты как в отдельности, так и в едином пространстве. Она полагает, что работа с терминами может происходить в других средах представления и коммуникации, что требует более широкого взгляда на терминологию. M.T. Кабре приводит в качестве примера таких случаев перевод текста с одного языка на другой, отмечая, что не все тексты, с которыми приходится работать специализированному переводчику, относятся к одному регистру общения, хотя все они имеют одинаковый уровень формальности, необходимый для профессионального общения и их разнообразие функций не требует одного и того же уровня специализации; кроме того, по многим предметам нет единого поля концептов [10].

Исходя из вышесказанного, М.Т. Кабре говорит о необходимости комплексной теории терминологии, которая будет учитывать когнитивные, лингвистические, коммуникативные сложности, возникающие в терминологии. Концепт, по мнению данного исследователя, не может выступать фактором разделения корпусов и баз специализированного знания. Наоборот, он выступает своеобразным местом и способом пересечения различных концептов из других баз и корпусов знаний. Функция концепта - установление новых связей значений с различными сферами знаний при одновременном сохранении возможных контекстуальных значений концепта в конкретной ситуации рассмотрения и употребления последнего без ущерба для аналогичных измерений последнего.

Одним из исследователей, кто обратил внимание на необходимость пересмотра трактовки концепта и его роли в терминологии, был Г. Пихт. Он пытался подчеркнуть, что концепт выступает своеобразным индикатором социальных и культурных трансформаций, которые сказываются на формировании значений в современной терминологии. Концепт Г. Пихтом определяется как единица знаний, созданная по уникальному сочетанию характеристик. При этом концепты не обязательно привязаны к определенным языкам. Однако на них часто влияет социальный или культурный фон, который приводит к разной классификации. Концепт характеризуется социальными факторами согласно эволюции общества и имеет свой жизненный цикл, который начинается с момента его возникновения и может закончиться в определенный момент. Однако концепт не умирает, он остается носителем знаний, относящихся к прежним стадиям познания, веры или эволюции [15].

М.Т. Кабре (она считается основоположником коммуникативного подхода к терминологическому планированию [16]), принимая интерпретацию концепта Г. Пихтом, полагает, что ограничиться только признанием зависимости последнего от социальных и культурных факторов недостаточно, поскольку важно учитывать коммуникативный и 
лингвистический аспекты функционирования терминологии, выражающие актуальные значения терминов в их динамике. Она обращается к поиску способа демонстрации того, как такого рода понимание концепта должно работать в терминологии. Для этого М.T. Кабре разрабатывает «теорию дверей» (The Theory of Doors) в качестве новой модели современного терминологического планирования.

Ключевым фактором теории дверей выступает понимание того, что значение термина не сводится к его изначальному денотату (но это не значит, что такого значения у термина нет), а формируется в процессе его использования и определяется соответствующим контекстом когнитивных, коммуникативных и лингвистических обстоятельств. Это наиболее значимые параметры, которые позволяют термину осуществлять свой жизненный цикл.

М.Т. Кабре вводит понятие «терминологические единицы», множественным числом обозначения подчеркивая сложность коммуникативных каналов, многообразие лексических значений и разнообразие контекстов применения. Она определяет терминологическую единицу как многогранное одновременное единство единиц знания, языка и общения. При таком подходе описание терминологической единицы обязательно должно охватывать эти три компонента: когнитивный, лингвистический, коммуникативный. Концепт, таким образом, понимается структурной составляющей терминологической единицы, но не единственной, поскольку он выражает, по мнению испанской исследовательницы, только когнитивный аспект, тогда как в ней присутствует лингвистический аспект (термин) и коммуникативный (ситуация). В такой системе концепт постоянно пребывает в незавершенном (открытом) состоянии, где изменение любого из аспектов демонстрирует изменение его самого. Теория и получила название теории дверей, поскольку термин формируется в процессе коммуникации, лингвистических трансформаций, ситуационных контекстов, где дверь просто обозначает наиболее вероятные каналы возможных изменений $[10,11]$.

Терминология в рамках теории дверей утрачивает прескриптивный характер, поскольку терминологическим единицам трудно что-то предписать, указать, каким должно быть значение. Это актуализирует динамический аспект функционирования современного общества, науки, собственно терминологического планирования, когда своевременная фиксация ситуативного (коммуникативный фактор), лингвистического (синтаксис, лексика, морфология и т. д.), когнитивного (система концептов) аспектов больше отражает оперативность деятельности терминолога, нежели его фундаментальность. В каком-то смысле терминологическая деятельность становится деятельностью всех участников когнитивного и коммуникативного процессов (в этом и проявляется основание для вывода об утрате терминологией статуса научности).

Но теория дверей М.Т. Кабре не единственная теория современного терминологического планирования, которая учитывает динамику развития современного общества, науки и знания. Есть и другие теории, которые пересматривают характер терминологической деятельности под влиянием происходящих изменений, просто они это делают, концентрируясь на их отдельных сторонах.

В частности, можно рассмотреть еще теорию Р. Тиммерман, К. Кереманса (теория социокогнитивного терминоведения) [17-19].

В рамках этой теории авторы стремятся также учесть ряд сдвигов, которые существенным образом повлияли на терминологию: сдвиг в сторону компьютерного управления терминологией, лингвистический сдвиг и онтологический сдвиг. Общая тенденция, которую авторы отмечают в развитии терминологии, - это переход от подхода, ориентированного на стандартизацию и концептуальность, к подходу, ориентирован- 
ному на общение и дискурс. Однако развитие информационных технологий (применение компьютеров) в терминологии позволяет отчасти реанимировать важную функцию стандартизации благодаря их возможностям. Другое дело, что эти возможности все равно носят ограниченный характер.

Эти же тенденции приводят к пересмотру понимания концепта и его места в терминологическом планировании. В рассматриваемой теории ключевым фактором становится термин (а не концепт), который интерпретируется как лингвистическое выражение в тексте. Р. Тиммерман, К. Кереманс вводят новое понятие - «единицы понимания» (units of understanding), которые состоят из концептов и категорий. Категории - это те концепты, которые имеют прототипы. Те же концепты, у которых нет прототипов, к категориям не относятся. Вводя единицы понимания, состоящие из концептов и категорий, Р. Тиммерман и К. Кереманс демонстрируют особенность терминологической деятельности в условиях ориентированности на общение и дискурс, а также необходимость учета ее осуществления в ситуации доминирования информационных технологий. Концепты как элементы единиц понимания актуальны для терминологической работы в дискурсивных практиках и неформализуемых базах данных, а категории в тех базах данных, которые формализуемы, и посредством терминологической работы трансформируются в базы знаний. Терминологическая деятельность понимается как семантически открытая деятельность описательного характера, но значение концепта в ней полностью не утрачивается.

Важным понятием для теории социокогнитивного терминоведения является понятие онтологии. Здесь имеет место семантическая близость с философским значением этого термина, терминологическая его трактовка носит частный характер относительно философского. Онтологией называется хранилище знаний, в котором определены категории (термины), а также отношения между этими категориями. Условно говоря, онтология - это база специализированных знаний, которая, с одной стороны, является основанием для терминологической деятельности, а с другой - одним из ожидаемых результатов этой деятельности.

В контексте теории социокогнитивного терминоведения терминологическое планирование представляется очень сложной деятельностью с привлечением терминологов, специалистов узких предметных областей, социологов, программистов и других специалистов.

Авторы разрабатывают специальный терминологический метод - термонтография. Они определяют ее как мультидисциплинарный подход, в котором теории и методы многоязычного терминологического анализа социокогнитивного подхода сочетаются с методами и руководящими принципами онтологического анализа. При применении метода термонтографии сначала идет подготовительная работа на этапах анализа и сбора информации; затем фактическая компиляция базы данных, состоящая из этапов поиска, уточнения и проверки; и, наконец, экспорт знаний из одно- или многоязычной терминологической базы данных в онтологию (базу знания) и терминологический словарь.

Тем самым авторы теории социокогнитивного терминоведения стремятся учесть происходящие социальные, когнитивные, лингвистические, коммуникативные изменения в контексте терминологической деятельности и сформировать в новых условиях наиболее работоспособную модель представления знаний и управлением этим процессом $[20]$.

Подводя итог, хочется констатировать, что ключевыми тенденциями в теориях терминологического планирования являются тенденции, связанные с когнитивными, 
лингвистическими, коммуникативными изменениями в социуме. Терминология эволюционирует от прескриптивной установки к дескриптивной, от статики семантической однозначности и стандартизации к динамике настоящего как ключевого фактора выявления значений термина и многозначности способов его применения. Это приводит к пересмотру роли в терминологии такого ключевого фактора, как концепт, разработке сложных моделей его включения в терминологическую деятельности, позволяющую учесть происходящие технологические, когнитивные, коммуникативные, лингвистические изменения.

В то же время нельзя считать, что эти тенденции являются однонаправленными. Если в одной теории (теория дверей М.Т. Кабре) речь идет об отказе от стандартизации как функции терминологического планирования, то в другой теории (социокогнитивной теории Р. Тиммерман, К. Кереманса) данная функция, пусть в несколько урезанном виде, но сохраняется благодаря современным информационным технологиям.

Учитывая рост информации и знания, с которыми современный мир столкнулся, актуальность терминологических теорий, а также способы их совершенствования будут только расти.

\section{СПИСОК ЛИТЕРАТУРЫ}

1. Ардашкин И.Б. Ценности современного образования как фактор развития: мировые тенденции и перспективы России // Вестник Томского государственного университета. - 2014. - № 384. - С. 60-67.

2. Манерко Л.А., Шарапков А.Н. Европейское терминоведение: от вюстерианского понимания термина к осмыслению когниции и коммуникации // Вестник МГОУ. Серия «Лингвистика». - 2015. - № 5. C. 24-32.

3. Gaudin F. Socioterminologia: um itinerário bem-sucecido // As ciências do léxico. Lexicologia, lexicografia, terminologia. - 2014. - № 7. - P. 293-309.

4. Найман Е.А. Критический анализ западноевропейской языковой идеологии (пролегомены к новой социальной онтологии языка) // Вестник Томского государственного университета. Философия. Социология. Политология. - 2019. - № 51- С. 53-69.

5. Wuster E. Introduction to the general theory of terminology and terminological lexicography. - Wien: Springer, 1979. - $176 \mathrm{p}$.

6. Felber H. Terminology manual. - Paris: UNESCO, 1984. - 426 p.

7. Sageder D. Terminology today: a science, an art or a practice? Some aspects on terminology and its development // Brno Studies in English. - 2010. - V. 36. - № 1. - P. 123-134.

8. Nedobity $\mathrm{W}$. The general theory of terminology: a basis for the preparation of classified defining dictionaries // Journal of the Dictionary Society of North America. - 1983. - № 5. - P. 69-75.

9. Manerko L. Concept understanding in cognitive linguistics and cognitive terminology science // Proc. of the 19th European Symposium on Languages for Special Purposes. Vienna, Austria, 8-10 July 2013. - P. 471-483. URL: http://lsp2013.univie.ac.at/proceedings (дата обращения 11.04.2021).

10. Cabré Castellví M.T. Theories of terminology. Their description, prescription and explanation // Terminology. - 2003. - № 9 (2). - P. 163-199.

11. Cabré M.T. Terminology and translation // Handbook of translation studies. - 2010. - № 1. - P. 356-365.

12. Myking J. Against precriptivism? The 'sociocritical' challenge to terminology // IITF Journal. - 2001. № 12(1-2). - P. 49-64.

13. Antia B.E. Terminology and language planning. An alternative framework of practice and discourse. - Amsterdam; Philadelphia: John Benjamins, 2000. - 290 p.

14. Budin G. A critical evaluation of the state-of-the-art of terminology theory // ITTF Journal. - 2001 № 12 (1-2). - P. 7-23.

15. Picht H. Concepts as reflection of societal changes // Terminologija. - 2013. - № 20. - P. 10-23.

16. Ахметова М.Э. Отечественный и зарубежный опыт изучения терминоведения: эволюция понятия «термины» в лингвистике // Грамота. Филологические науки. Вопросы теории и практики. URL: https://www.gramota.net/materials/2/2014/8-1/4.html (дата обращения 07.04.2021).

17. Temmerman R., Kerremans K. Termontography: ontology building and the sociocognitive approach to terminology description // Proceedings of CIL17. - 2003. - V. 7. - P. 1-10. URL: 
https://www.academia.edu/851013/Termontography_Ontology_building_and_the_sociocognitive_approach to_terminology_description (дата обращения 10.04.2021).

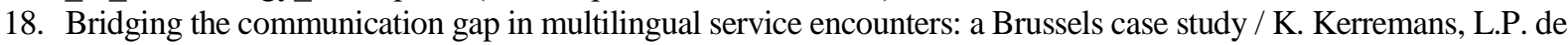
Ryck, V. de Tobel, R.J. Anssens, P. Rillof // The European Legacy. - 2018. - № 23 (7-8). - P. 757-772.

19. Temmerman R. Co-creation and Web 2.0. Brand names for new craft beers in the multilingual city of Brussels // Ela. Etudes de linguistique appliquee. - 2018. - № 4. - P. 417-434.

20. Kageura K. Terminology and lexicography // Handbook of terminology. - 2015. - № 1. - P. 45-59.

Поступила 12.04.2021 2. 
UDC 81'271

\title{
TO THE ISSUE OF KEY TRENDS IN FOREIGN THEORIES OF TERMINOLOGICAL PLANNING: SOCIOLINGUISTIC ASPECT
}

\author{
Igor B. Ardashkin, \\ ibardashkin@tpu.ru \\ National Research Tomsk Polytechnic University, \\ 30, Lenin avenue, Tomsk, 634050, Russia
}

Igor B. Ardashkin, Dr. Sc., professor, National Research Tomsk Polytechnic University.

Relevance. Theories of terminological planning are analyzed from the position of the sociolinguistic approach. The importance of the analysis is caused by the revision of the nature of terminological activity associated with the ongoing cognitive, linguistic, communicative changes in the process of cognitive activity of a person and society, as well as the intensity of informatization. The purpose of the article is to determine the main trends in the development of terminological activity and ways of displaying the indicated trends in foreign theories of terminological planning. A sociolinguistic approach is used as the main research methods. Its main feature is to establish the dependence of linguistic transformations on social processes and vice versa. A comparative approach is also used in relation to comparing the main theories of terminological planning for the display of cognitive, informational, linguistic and communicative changes in them. Ontognoseological foundations are used as a criterion for comparing these theories, demonstrating the influence of ontological structures of terminological activity on the epistemological aspect of its implementation. Results. The main trends in terminological activity were identified, and one classical theory (general theory of terminology by E. Wüster) and two modern theories of terminological planning (door theory by M.T. Cabre and sociocognitive theory by R. Timmerman, K. Keremans) were analyzed. A comparative analysis of these theories was carried out. As a result the transformation of the idea of a concept was determined: from the key parameter of terminological planning in the theory of E. Wüster, which prescribes its semantic content in a prescriptive manner to any term, to one of the key components of a terminological nature, through which, among other things, the semantic content of the term id determined (described), rather than prescribed. Conclusions. The revision of the status of the idea of a concept in terminological planning does not lead to the fact that the trends are unidirectional. These trends indicate to a greater extent that the ongoing changes in cognitive, communicative, linguistic representations in terminological planning are of a multidirectional nature. In the theory of doors, M.T. Cabre argues that standardization is no longer a necessary component of terminological planning, and in the sociocognitive theory of R. Timmerman, K. Keremans, it is believed that thanks to information technologies, standardization procedures are quite achievable in the new conditions of the implementation of terminological activities.

Key words: Terminological planning, general theory of terminology, terminological theory of doors, sociocognitive theory of terminology, concept.

\section{REFERENCES}

1. Ardashkin I.B. Tsennosti obrazovaniya kak faktor razvitiya: mirovye tendentsii i perspektivy Rossii [Values of modern education as a factor of development: global trends and prospects of Russia]. Vestnik Tomskogo gosudarstvennogo universiteta, 2014, no. 384, pp. 60-67.

2. Manerko L.A., Sharapkov A.N. Evropeyskoe terminovedenie: ot vyusterianskogo ponimaniya termina $\mathrm{k}$ osmysleniyu kognitsii i kommunikatsii [European terminology: from the Wüsterian understanding of the term to the understanding of cognition and communication]. Vestnik MGOU. Seriya «Lingvistika», 2015, no. 5, pp. 24-32.

3. Gaudin F. Socioterminologia: um itinerário bem-sucecido [Socioterminology: a successful itinerary]. As ciências do léxico. Lexicologia, lexicografia, terminologia, 2014, no. 7, pp. 293-309. 
4. Nayman E.A. Kriticheskiy analiz zapadnoevropeyskoy yazykovoy ideologii (prolegomeny k novoy sotsialnoy ontologii yazyka) [Critical analysis of Western European linguistic ideology (prolegomena to a new social ontology of language)]. Vestnik Tomskogo gosudarstvennogo universiteta. Filosofiya. Sotsiologiya. Politologiya, 2019, no. 51, pp. 53-69.

5. Wuster E. Introduction to the general theory of terminology and terminological lexicography. Wien, Springer, 1979. $176 \mathrm{p}$.

6. Felber H. Terminology manual. Paris, UNESCO, 1984. 426 p.

7. Sageder D. Terminology today: a science, an art or a practice? Some aspects on terminology and its development. Brno Studies in English, 2010, vol. 36, no. 1, pp. 123-134.

8. Nedobity W. The general theory of terminology: a basis for the preparation of classified defining dictionaries. Journal of the Dictionary Society of North America, 1983, no. 5, pp. 69-75.

9. Manerko L. Concept understanding in cognitive linguistics and cognitive terminology science. Proc. of the $19^{\text {th }}$ European Symposium on Languages for Special Purposes. Vienna, Austria, 8-10 July 2013. pp. 471-483. Available at: http://lsp2013.univie.ac.at/proceedings (accessed 11 April 2021).

10. Cabré Castellví M.T. Theories of terminology. Their description, prescription and explanation. Terminology, 2003, no. 9 (2), pp. 163-199.

11. Cabré M.T. Terminology and translation. Handbook of translation studies, 2010, no. 1, pp. 356-365.

12. Myking J. Against precriptivism? The 'Sociocritical' Challenge to Terminology. IITF Journal, 2001, no. 12 (1-2), pp. 49-64.

13. Antia B.E. Terminology and language planning. an alternative framework of practice and discourse. Amsterdam, Philadelphia, John Benjamins, 2000. 290 p.

14. Budin G. A critical evaluation of the state-of-the-art of terminology theory. ITTF Journal, 2001, no. 12 (1-2), pp. 7-23.

15. Picht H. Concepts as reflection of societal changes. Terminologija, 2013, no. 20, pp. 10-23.

16. Akhmetova M.E. Otechestvenny i zarubezhny opyt izucheniya terminovedeniya: evolyutsiya ponyatiya «termin» v lingvistike [Domestic and foreign experience in studying terminology: evolution of the concept of «term» in linguistics]. Gramota. Filologicheskie nauki. Voprosy teorii i praktiki. Available at: https://www.gramota.net/materials/2/2014/8-1/4.html (accessed 7 April 2021).

17. Temmerman R., Kerremans K. Termontography: ontology building and the sociocognitive approach to terminology description. Proceedings of CIL 17, 2003, vol. 7, pp. 1-10. Available at: https://www.academia.edu/851013/Termontography_Ontology_building_and_the_sociocognitive_approach _to_terminology_description (accessed 10 April 2021).

18. Kerremans K., De Ryck L.P., De Tobel V., Anssens R.J., Rillof P. Bridging the communication gap in multilingual service encounters: a Brussels case study. The European Legacy, 2018, no. 23 (7-8), pp. 757-772.

19. Temmerman R. Co-creation and Web 2.0. Brand names for new craft beers in the multilingual city of Brussels. Ela. Etudes de linguistique appliquee, 2018, no. 4, pp. 417-434.

20. Kageura K. Terminology and lexicography. Handbook of terminology, 2015, no. 1, pp. 45-59.

Received: 12 April 2021. 